\title{
ENTRY RELATED INJURIES AND PORT SITE HERNIAS IN LAPAROSCOPIC PROCEDURES: A REVIEW OF 100 CASES
}

\author{
Ramula Muthammal1, Joyce Prabhakar Joseph ${ }^{2}$ \\ ${ }_{1}^{1}$ Associate Professor, Department of General Surgery, Government Chengalpattu Medical College Hospital. \\ ${ }^{2}$ Assistant Professor, Department of General Surgery, Government Chengalpattu Medical College Hospital.
}

\section{ABSTRACT}

\section{OBJECTIVE}

This prospective clinical trial was conducted to evaluate the incidence of intraperitoneal injuries with the use of closed Veress needle technique in primary port placement, the incidence of Port Site Hernias (PSH) and the efficacy of fascial closure in the prevention of PSH.

\section{METHODS}

A total of 100 patients undergoing various laparoscopic procedures were enrolled in the study, which included Cholecystectomy, Appendectomy, Adhesiolysis and diagnostic procedures. All surgeries were done on selective basis. Fascial closure was not done in any of the cases and no Endobag was used to retrieve the specimens. In the event of difficulty in retrieving the specimen, port site was extended by 2 or $3 \mathrm{~mm}$ to facilitate easy removal. The period of study was from October 2013 to March 2015 at The Government Chengalpattu Medical College and Hospital. The incidence of injuries to the intraperitoneal structures during the primary port insertion by the closed Veress needle technique and the incidence of PSH were observed.

\section{RESULTS}

There was no incidence of bowel or vascular injuries with the use of the closed Veress needle technique or PSH in all the 100 patients $(0 \%)$. The advantages of fascial closure in preventing PSH is questionable.

\section{CONCLUSION}

Closed method of primary port insertion using the Veress needle is a very safe method with the appropriate technique. The efficacy of closure of fascial layer in preventing trocar site hernias is a subject of debate and needs further evaluation since our study was restricted to basic laparoscopic procedures done on elective basis and no comparative analysis was made with the open method.

\section{KEYWORDS}

Laparoscopy, Veress Needle, Port Site Hernias (PSH), Complications.

HOW TO CITE THIS ARTICLE: Muthammal R, Joseph JP. Entry related injuries and port site hernias in laparoscopic procedures: a review of 100 cases. J. Evolution Med. Dent. Sci. 2016;5(34):1885-1887, DOI: 10.14260/jemds/2016/445

\section{INTRODUCTION}

Abdominal access and the creation of a pneumoperitoneum in the initial stage of any laparoscopic surgery carry a significant risk of bowel and vascular injuries and majority of these complications occur prior to commencement of surgery.[1,2] This complication rate remains a nightmare, especially for the beginners. Increased morbidity and mortality result when surgeons do not recognise injuries early.[3] The overall incidence of laparoscopic entry injuries ranges from 1.4 per 1,000 to 5.7 per 1000 cases as reported by various centres. Several techniques, instruments and approaches have been introduced to minimise entry related injuries. These include the classic closed entry, Hasson open method, safety (Sheathed) trocars, Optical Veress and optical trocars.[4,5,6] Each of these methods enjoy a variable degree of popularity depending on the surgeon's expertise and availability. By far the most common entry related injury is to the bowel followed by vascular injuries. The mortality rate of undiagnosed injuries vary from $5 \%$ with bowel injuries to $15 \%$ with vascular injuries.[7]

Financial or Other, Competing Interest: None.

Submission 12-03-2016, Peer Review 07-04-2016,

Acceptance 12-04-2016, Published 27-04-2016.

Corresponding Author:

Dr. Ramula Muthammal,

A 14, Old G. S. T. Road, Alagesan Nagar,

Chengalpattu-603001, Tamilnadu.

E-mail: ramuladurai@gmail.com

DOI: $10.14260 /$ jemds/2016/445
The incidence of PSH ranges from $0.14 \%$ to as high as $22 \% .[8,9,10]$ Though several earlier reports reported an overall incidence of $1.7 \%$ with various laparoscopic procedures.[11,12,13] These hernias can be complicated by obstruction and strangulation.[14,15,16] The umbilicus was by far the most common port to be associated with incisional hernia, However, hernias were observed at all other sites including the epigastrium, the right and left hypochondrium.[17,18,19]

The interval between operation and diagnosis of PSH varies between studies and depends on follow-up regimes. The time to diagnosis ranges from 5 days to 3 years with an average of 9.2 months.[17] Predisposing factors of PSH include pre-existing umbilical fascial defects, obesity, need to extend the incision to retrieve larger organs, trocar diameter, reinsertion of ports, wound infection and older age with comorbid diseases.[17,20] Gender difference has not been shown to contribute significantly towards the incidence of PSH.[20,21] Some studies insist on fascial closure to prevent the incidence of $\mathrm{PSH}$, whilst some others have documented unobliterated fascial defects have not been quite effective in preventing PSH.[21]

\section{MATERIALS AND METHODS}

This prospective randomised study includes 100 consecutive cases of laparoscopic procedures done on an elective basis. There were 59 females and 41 males. 
Procedures performed include appendectomies 52, cholecystectomies 38, adhesiolysis 7 and diagnostic procedures 3. The period of study was from October 2013 to March 2015. The mean follow-up period was 13.4 months. The primary port insertion was supraumbilical in $80 \%$ of the cases. In the remaining $20 \%$ of the cases with history of previous surgeries, the primary ports were placed slightly higher or in a suitable place which included few $\mathrm{cms}$ above the umbilicus (12 cases) and other regions including the epigastric ( 5 cases), left hypochondriac ( 2 cases) and left lumbar region (1 case). Cholecystectomies were done by the standard 4 port method with two $10 \mathrm{~mm}$ ports and two $5 \mathrm{~mm}$ ports. We routinely use the subxiphoid port to extract the gall bladder specimen.

In case of large stone hindering easy removal of specimen, a 2 to $3 \mathrm{~mm}$ extension of incision was made (11 cases). For appendectomies we use two $10 \mathrm{~mm}$ ports, one at the umbilicus (Primary port) and one at the left iliac fossa and one $5 \mathrm{~mm}$ port at the right hypochondriac region. We avoid using a right iliac/suprapublic port, because we reckon it is more difficult to manoeuvre the instruments in these sites owing to the proximity to the target organ. Fascial closure was not done in any of the cases and the skin was closed using single mattress sutures for the $10 \mathrm{~mm}$ ports and a single simple suture for the $5 \mathrm{~mm}$ ports. Extended subxiphoid ports were closed with 2 interrupted mattress sutures. Cases which required conversion into open surgeries were excluded from the study.

\section{DISCUSSION}

With the appropriate classic closed technique of the primary port placement using the Veress needle in about 100 cases of laparoscopy, we experienced no bowel or vascular injuries. While entering, the parietes is lifted using the left hand of the surgeon at the umbilicus. This gives a definitive lift of all the layers since all the layers of the parietal wall are fused together in this region. The needle is usually directed 15 to 20 degrees caudally to avoid injury to the aorta or iliac vessels. ${ }^{[22,23,24]}$ The hand usually rests over the abdominal wall since this prevents overshooting of the needle.

Passing directly through the umbilicus is usually avoided since the umbilicus being a natural scar resists easy entry and needs considerably greater force, which may predispose to injuries. We prefer supraumbilical site for the primary port, though it has a slight theoretical disadvantage than the infraumbilical region due to presence of falciform ligament. But, in our experience it has never been an issue whatsoever. We set the intra-abdominal pressure in adults to a standard 15 $\mathrm{mmHg}$, in children we set a lower value depending on age and build of the patient.

Trocars are introduced in a similar 15 to 20 degrees caudal direction. The first stage of lap surgery should be to inspect the structures underneath the primary entry site for any inadvertent injuries, since late recognition or failure to recognise injuries carry an even worse outcome.[3] We have never closed the fascial layer in any of the 100 cases, be it 5 $\mathrm{mm}$ or $10 \mathrm{~mm}$ or ports which needed a further few mms of extension. After a mean follow-up period of 13.4 months, there has been no case of PSH in our study. It is difficult to draw a definitive conclusion on the role of fascial closure in preventing PSH on the basis of our study as the volume of the cases is not too big and was restricted to basic procedures with a mean operating time of 40 minutes.
All procedures have their risks. Complications can occur even in the best of hands and it is vital that these are minimised by scientifically precise techniques and complications recognised promptly and appropriately dealt with. The importance of good training and the value of experience is conspicuous.

\section{REFERENCES}

1. Jansen FW, Kapiteyn K, Trimbos-Kemper $\mathrm{T}$, et al. Complications of laparoscopy: a prospective multicentre observational study. $\mathrm{Br} \quad \mathrm{J}$ Obstet Gynaecol 1997;104(5):595-600.

2. Jansen FW, Kolkman W, Bakkum EA, et al. Complications of laparoscopy: an inquiry about closed versus open-entry technique. Am J Obstet Gynaecol 2004;190(3):634-8.

3. Fuller J, Scott W, Ashar B, et al. Laparoscopic trocar injuries: a report from a US FDA center for devices and radiological health (CDRH) systematic technology assessment of medical products (STAMP) committee. 2005;1-14.

4. McGurgan P, O'Donovan P. Optical Veress as an entry technique. Gynaecol Endosc 1999;8(6):379-82.

5. Mettler I, SchmidtEH, Frank V, et al. Optical trocar systems: laparoscopic entry and its complications. Gynaecol Endosc 1999;8(6):383-9.

6. Lanvin D, Elhage A, Querleu D. Does the use of pneumoperitoneum and disposable trocars prevent bowel injury at laparoscopy a randomised experimental study in the rabbit? Gynaecol Endosc 1996;5(6):343-8.

7. Chandler JG, Corson SL, Way LW. Three spectra of laparoscopic entry access injuries. J Am Coll Surg 2001;192(4):478-90.

8. Hussain A, Mahmood H, Singhal T, et al. Long-term study of port-site incisional hernia after laparoscopic procedures. JSLS 2009;13(3):346-9.

9. Johnson WH, Fecher AM, McMahon RL, et al. Versa step TM trocar hernia rate in unclosed fascial defects in bariatric patients. Surg Endosc 2006;20(10):1584-6.

10. McMurrick PJ, Polglase AL. Early incisional hernia after use of the $12 \mathrm{~mm}$ port for laparoscopic surgery. Aust NZ J Surg 1993;63(7):574-5.

11. Voyles CR, Petro AB, Meena AL, et al. A practical approach to laparoscopic cholecystectomy. Am J Surg 1991;161(3):365-70.

12. Baird DR, Wilson JP, Mason EM, et al. An early review of 800 laparoscopic cholecystectomies at a universityaffiliated community teaching hospital. Am Surg 1992;58(3):206-10.

13. Larson GM, Vitale GC, Casey J, et al. Multipractice analysis of laparoscopic cholecystectomy in 1,983 patients. Am J Surg 1992;163(2):221-6.

14. Lee JH, Kim W. Strangulated small bowel hernia through the port site: a case report. World J Gastroenterol 2008;14(44):6881-3.

15. Uslu HY, Erkek AB, Cakmak A, et al. Trocar site hernia after laparoscopic cholecystectomy. J Laparoendosc Adv Surg Tech A 2007;17(5):600-03.Duron JJ, Hay JM, Msika S, et al. Prevalence and mechanism of small intestinal obstruction following laparoscopic abdominal surgery: a retrospective multicenter study. French Association for Surgical Research Arch Surg 2000;135(2):208-12. 
16. Coda A, Bossotti M, Ferri F, et al. Incisional hernia and fascial defect following laparoscopic surgery. Surg Laparosc Endosc Percutan Tech 2000;10:34-8.

17. Balakrishnan S, Samdani T, Singhal T, et al. Patient experience with gallstone disease in a national health service district hospital. JSLS 2008;12(4):389-94.

18. Sanz-Lopez R, Martinez-Ramos C, Nunez-Pena JR, et al. Incisional hernias after laparoscopic vs open cholecystectomy. Surg Endosc 1999;13(9):922-4.

19. Nassar AH, Ashkar KA, Rashed AA, et al. Laparoscopic cholecystectomy and the umbilicus. $\mathrm{Br} J$ Surg 1997;84(5):630-3.

20. Azurin DJ, Go LS, Arroyo LR, et al. Trocar site herniation following laparoscopic cholecystectomy and the significance of an incidental preexisting umbilical hernia. Am Surg 1995;61(8):718-20.
21. Richardson RF, Sutton CJG. Complications of first entry: a prospective laparoscopic audit. Gynaecol Endosc 1999;8(6):327-34.

22. Molloy D, Kaloo PD, Cooper M, et al. Laparoscopic entry: a literature review and analysis of techniques and complications of primary port entry. Aust N Z J Obstet Gynaecol 2002;42(3):246-54.

23. Hurd WW, Bude RO, DeLancey JO, et al. The relationship of the umbilicus to the aortic bifurcation: complications for laparoscopic technique. Obstet Gynaecol 1992;80(1):4851. 